\title{
OH\&S IN SMALL AND \\ MEDIUM-SIZE ENTERPRISES \\ AND THE ISSUE OF \\ CULTURAL DIVERSITY: \\ ONGOING RESEARCH IN THE \\ CONSTRUCTION INDUSTRY
}

\author{
Christophe Martin ${ }^{\mathrm{a}, \mathrm{b}}$ \\ *Melchior Pelleterat de Borde ${ }^{\mathrm{a}}$, \\ Franck Guarnieri ${ }^{\mathrm{a}}$, Felicity Lamm ${ }^{\mathrm{c}}$ \\ ${ }^{\text {a } C r i s i s ~ a n d ~ R i s k ~ r e s e a r c h ~ C e n t r e, ~}$ \\ Mines ParisTech, \\ Rue Claude Daunesse, BP207 \\ 06904 Sophia Antipolis, Cedex, France \\ ${ }^{\mathbf{b}}$ ESAIP Grasse - Engineering School \\ ISP Fénelon \\ ${ }^{\mathbf{c}}$ School of Business - Management \\ Auckland University of Technology
}

\begin{abstract}
This paper reports on the findings from stage one of a collaborative New Zealand and French research project on the construction industry and in particular the link between occupational health and safety (OHS), subcontracting and cultural diversity. The construction sector in France, New Zealand and elsewhere has not only one of the highest injury, illness and fatality rates but the sector also has a prevalence of small subcontracting firms and a substantial migrant labour force (CNAM, 2008; Department of Labour, 2009). The practice of outsourcing in this industry has created a complex web of sub-contracting with an international dimension and resultant confusion over regulatory responsibilities for the health and safety of workers. Thus, those in the industry are grappling with challenges of managing a culturally diverse workforce within a hazardous working environment.
\end{abstract}

Hiring poorly paid migrant labours in the construction industry, however, is not a recent phenomenon in either France or New Zealand. This in turn has created a melting pot where diversity can be both an advantage and a weaknesses in terms of safety. One the on hand the enormous variability of demographic and social status (Jounin, 2009) and cultures (a term which here encompass personal, collective and professional elements) can lead to dissonance on construction site and yet on the other hand diversity can stimulate innovative ways of implementing safety measures more effectively (Mearns and Yule, 2009). Given that the international subcontracting process and migrant labour are central to the construction industry, the aim of this qualitative research is to identify and explain the sources of OHS failure and suggest adjustments that need to be made.

\section{Introduction}

Almost 175 million people or $3 \%$ of the world population is currently living outside their country of origin. The movement of goods and facilities was the symbolic element of the globalizing society, our economy is now defined by an almost boundless mobility of both goods, tools, workers and organisations. Such a tremendous evolution does not solely impact social or political issues regarding living conditions and integration of the immigrants. The increasing global mobility and its linked diversity in the workplace also raise economical issues in terms of efficiency, safety and team management. The first intercultural management studies, such as IBM for Hofstede's innovative work (Hofstede, 1980) were focusing on large companies, and the mergers and acquisitions movement during the 1980's confirmed the interest for that subject. 
Recently, an international cluster was created to investigate and share both results and experiences on the Occupational Health and Safety (OH\&S) of migrant workers in precarious, non-standard employment located in small businesses, such as what can be observed in the construction industry (Lamm, Martin and Shulruf, 2009; Boocock et al., 2010). Beyond differences due to local historical and geographical contexts, be it the inner diversity in New Zealand, the EU or African migrations to France or other culturallymixed environments, common theoretical schemes can be used to assess the impact of cultural diversity on the $\mathrm{OH} \& \mathrm{~S}$ of migrant workers in Small and Medium-size Enterprises (SMEs). Diversity - which here encompasses personal, collective as well as professional culture - can lead to dissonance on the working site as it can stimulate innovative ways of implementing safety measures more effectively (Mearns and Yule, 2009).

Our research project stands on the hypothesis of an influence of cultural diversity on risk perception and behaviours of workers, which be either a benefit or a weakness for risk management and safety in the construction sector. As our previous explorative interviews show, there is a huge need of knowledge on the way diversity, culture, values and safety interact. As managers point out their inability to master informal systems, we aim at investigating the potential introduction of communication circuits among workers which overtake institutional ones, thus creating disharmony between the two systems.

This paper will first present research references regarding the link between cultural diversity and the OH\&S concern. Two domains must be distinguished: on the one hand, the impact of migration on the worker himself, which is apparently a negative influence: Sargeant and Tucker (2009) give us an interesting presentation of that domain when speaking of "layers of vulnerability"; on the other hand, we must take into account the impact of migrants' employment on the working site. That second domain is a more ambiguous one, probably including both good and bad outcome of cultural diversity of the work environment.

The second part of the paper will deal with the specific position of the construction sector, as a relevant research field to collect data on cultural diversity and $\mathrm{OH} \& \mathrm{~S}$ risks. It is characterised by a great diversity of status and origin of workers, complex and evolving formal and informal systems, enterprises of various sizes - but a majority of small structure - and multiple site configurations. It is also both the industrial sector with the highest injury, illness and fatality rates and a strong internationally shared concern, with every single country confronted to those challenges.

Finally, the paper will present an on-going qualitative research focusing on the French construction sector.

\section{Cultural diversity, migration, and risk management}

Since the 1970's, the issue of culture has been part of the management thinking (Hofstede, 1980; D'Iribarne, 1989; Chevrier, 2003). Taking into account the cultural factor when proceeding to enterprises merging started to be seen as necessary, since almost half of such operations are seen as failure. The example of the European consortium EADS (created by merging the French Aérospatiale-Matra, the German DASA and the Spanish CASA) shows the potential obstacle to mergers and acquisitions due to the cultural gap (Barmeyer et al. 2002).

The issue of cultural diversity and its link to OH\&S are consequences of the new evolution of the world economy, where no activity can be carried out regardless of the global environment. As Hofstede's works showed the necessity to take into account the cultural specificities of nations when exporting management tools and organisations (Hofstede, 1980, 2001), the current subcontracting system imposes to integrate the idea of cultural diversity into our actions of prevention. Diversity is not only to be found when enterprises increase their influence outside local, regional and national borders, by clinching contracts with international partners. For instance, more and more enterprises employ foreign born workers, regardless their status. A renewed fact to be dealt with is the growing diversity of cultures, work experiences and risk perception inside working sites, such as the construction sites. In Europe, the enlargement of the European Union brought many different national groups to move from countries to countries and eased the employment of foreign-born workers. At the end of the 1990 's, $50 \%$ of the immigrants to France originated the EU (INSEE 1995), and $15 \%$ of the immigrants worked in the construction industry $(7 \%$ for the overall French population). Since then, 12 countries integrated the common market, thus increasing the exchanges (Jounin, 2009).

The current researches on cultural diversity do not only deal with the confrontation of cultural background in merged enterprises, but are beginning to pay attention to the benefits or weaknesses diversity brings. As an increasing number of migrant workers integrated local markets - even temporally - due to legal migration, family reunification, unauthorized immigration or international subcontracting, the issue of cultural diversity and of its management evolved. The developed countries' industries experience a quantitative leap of migrant workers inside their teams, albeit some, like the construction industry, service to private individuals, food processing industry and agriculture already have a long history of migrants employment. Following Sargeant and Tucker (2009), we define migrant workers as:

"...workers who have migrated to another country to take up work but who currently do not have a permanent status in the receiving country... The migrant category... includes both workers who have obtained a legal right to enter and work, as well as 
those who have entered and are working without legal authorisation. It also includes temporary foreign workers (TFWs) whose right to work is time-limited from the outset, as well as foreign workers who have a more open-ended right to remain but have not yet obtained permanent status". (Sargeant and Tucker, 2009:52)

The relationship between $\mathrm{OH} \& \mathrm{~S}$ and cultural diversity could be presented in a pedagogical way by distinguishing two very different aspects.

One the one hand, migrant workers experience specific work conditions and $\mathrm{OH} \& \mathrm{~S}$ risk vulnerability. A regular observation made by researchers is that migrant workers tend to loose their status after migration and are more often employed in low-skilled and low-paid occupations and in small structures, jobs often called the 3D jobs (standing for Dirty, Dangerous and Demanding jobs) (Tavan, 2006; OECD, 2007; Irastorza, 2010). Difference also concerns the exposition to hazardous, monotonous, isolated and life-threatening work conditions (Quinlan et al., 2001; McKay et al. 2006; DARES, 2009; Smith et al., 2010). As a consequence, the accident, illness and fatality rates for migrant workers are higher, even if, as Walters (2001) rightfully points out, it is difficult to estimate the actual number of accidents involving migrants, especially in small enterprises. As Berretima (2009) shows, migrants are sometimes in precarious situations which prevent them from declaring accidents, because of a fear of loosing their job. An accident for migrant workers is not only a health problem and a loss of resources, but also an additional factor of vulnerability (Berretima, 2009). Isolation and language barriers also make it harder for workers to obtain recognition and compensations for occupational injuries and illnesses. For them, as they are more mobile than other workers, proving a link between the suffered affections and a responsible employer is a difficult task. Sargeant and Tucker (2009) propose a relevant summary of those specific conditions, by speaking of "Layers of vulnerability". Three layers are exposed: 1) the "Migration factors", the legal employment and immigration status of the worker (contract length and protections, authorized or unauthorized immigration); 2) the "Migrant worker factors", their personal and cultural background (economic and social situation, characteristics of the country of origin) and 3 ) the "Receiving country factors" (such as socio-economic situation, sectors of employment and immigrants' perception among the local population) (Sargeant and Tucker, 2009). In that perspective, a migrant worker can be seen as bearing a "fate" of vulnerability, he is vulnerable per se since the sometimes degrading process of migration lead him to be employed in depreciated jobs.

On the other hand, the diversity brought by culturally diverse workers is believed to have an impact on the OH\&S management on working sites. In our research, cultural diversity encompasses various aspects of the workers's personal background and of the groups' characteristics. The group has to be seen as the group the workers feels or claim he belongs to or the group the worker is said he belongs to. Three kind of cultural factors can be distinguished to be used in our research: 1) the person-centred factors, such as the socio-economic situation of the worker, his own personal and migration history, suffered accidents, education, age, cognitive system of beliefs, risk perception, values, judgements and prejudice; 2) the cultural group or national group-centred factors, such as language, the ability to support one of its member in case of need, the perceived status of the group among local population (hostility, friendship, prejudices); 3 ) the professional or corporatists factors, which represent the working experience of people regarding the enterprises size, the affiliation to a professional group with its habits, codes, representations and customs, and the mastered formal and informal systems within the workplace. This said, one can realize that our perception of the cultural diversity brings together various elements allowing both potential divergence and convergence. Diversity can not be reduced to an argument of vulnerability, and has to be considered as a more ambivalent concept. Be it the personal experience of workers, the relative good practice of the country of origin or simple safe habits a professional group, diversity is in the mean time including potential miscommunication problems, dissonance or hostility and potential contribution to safer attitude. As Kouabenan (2009) points out, the increasing diversity in the workplace challenges the prevention measures' implementation. Workers balance the opportunity of adopting safer behaviours with regard to their feeling of the incurred risk, their experience and the relative assessed priorities of their two work objectives: productivity and safety (Daveziès, 1997).

When crossing these two perspectives, the inherent vulnerability of migrant workers and the actual impact of cultural factors on risk perception and $\mathrm{OH} \& \mathrm{~S}$ prevention measures, we can have a clearer vision of the complex system at stake. For example, unemployment rates and poorer living conditions for migrants are an argument for an increased risk acceptance level (Kouabenan, 2009) which then impacts safety measures' implementation.

As seen previously some industrial sectors gather most of the aforementioned factors. The construction sector, is has been said, is a relevant research field to collect data regarding the interaction between cultural diversity and $\mathrm{OH} \& \mathrm{~S}$ risk management. It is a clear internationally shared concern, with every single country confronted to OH\&S challenges in that industry.

\section{The construction sector in France: context and $O H \& S$ concern in relation to cultural diversity}

The French construction sector is characterized by a great diversity of status and origin of workers, complex and evolving formal and informal systems, enterprises of various sizes - but a majority of small structure - and multiple site configurations. 
With 1.7 million workers, the construction sector is one of the dominant sectors of the French economy (INSEE, 2009). The Construction sector represented almost $10 \%$ of the French GDP in 2007 (Commissariat Général au Développement Durable, 2009). It is of crucial importance for the French economy as it is for other countries. But the construction industry also suffers the highest occupational injury, illness and fatality rate. It is estimated that $8 \%$ to $10 \%$ of all the French workers are employed in that industry (OPPBTP, 2009; Ministère de l'Economie, 2009), while almost $20 \%$ of the injuries in France in 2008 occurred in that sector (OPPBTP, 2009). Incidentally, that situation led the national and international institutions (European Union, ILO) to focus namely on the construction sector, as well as other dangerous sectors, to reduce its $\mathrm{OH} \& \mathrm{~S}$ toll.

The subcontracting system is in the French construction industry an overwhelming paradigm. First, it is dominated by SMEs. $98.5 \%$ of all enterprises in the construction sector are SMEs (they employ less than 250 employees), 96\% employ less than 20 employees, and $81 \%$ less than 4 employees. Of those $81 \%, 1 / 3$ employ from 1 to 3 employees, and $2 / 3$ have no employee at all. $75.6 \%$ of employees work in independent SMEs, and $16.6 \%$ in larger firms (Ministère de l'Economie, 2009). The massive presence of SMEs in the construction sector's environment raises problems in terms of control and enhances diversity. Quite often, leading firms invite their own workers to become independent contractors, thus gaining a great flexibility of "employment" but losing in the mean time the control on workers qualifications and safety formations (Green, 2000).

With a growing subcontracting web expanding beyond national borders, major construction firms have no means to assess the various levels of subcontracts in the supply chain (Quinlan and Thébaud-Mony, 2010). Due to the French law on subcontracting, enterprises have an obligation to declare their contracting firms to the master-builder. But the obligation is not systematically complied, since the declaration lead to reveal the margins taken, and because some of the contracts are signed afterward, or not at all. Subcontractors have little means to impose a declaration in a context of strong concurrence. Even if the subcontracting enterprise is declared to the master-builder, the reported information only concerns the number of workers supposed to be onsite, never their names or qualifications. They thus may be employees of the subcontractor or temporary workers, documented or undocumented workers. Our interviewees confirmed the fact that they had no precise idea of who would work onsite after they accept the presence of a subcontractor. Unless they have a particular reason to do so, they never refuse to validate the choices made by their own contractors. As a consequence, the master-builder has no control of the employment situation in its construction sites. Subcontractors have a complete freedom to employ the workers they need as soon as they comply with their contractual obligations. Our interviews confirmed that managers and safety engineers know more about "companions" (the regular workers in the construction sector's major firms) than about any other worker employed by SMEs in the working site, be they subcontractors or temporary workers, declared workers or not. They have a clear tendency of non-apprehension of the potentially aggravating or improving influence of cultural diversity on risk perception, $\mathrm{OH} \& \mathrm{~S}$ risk prevention and safety implementation.

The construction sector is largely dominated by small firms. As simple structures, it as been said that SMEs can provide favourable environment to put cultural diversity into good use. They can quickly change their organisation, habits, procedures, and are more responsive compared to larger firms. Diversity of experience, education, culture, may be used to feed a reflection on the methods employed by the enterprise to deal with safety measures and risk management (Lamm, Martin and Shulruf, 2009).

The subcontracting system lead to a transfer of economic pressure and $\mathrm{OH} \& \mathrm{~S}$ responsibility from leading firms to smaller enterprises, which have a lack of safety competences, possess simpler management systems, have reduced margins and means and suffer a stronger competitive environment (Eakin, 1992; Champoux and Brun, 2000; Lamm, 2002). The general structure of the construction sector prompts the small enterprises to accept cheaper markets while taking responsibility for the OH\&S issues rose. The employees recruitment is then fractioned between permanent employees and precarious workers, who can be temporary workers from agencies or casual workers enrolled "on the go", when needed (Jounin, 2009).

The construction of interaction patterns, of common schemes of comportment is made difficult because the work environment is defined by a restrictive temporality, an atomised interest (to make the job, regardless to other workers from different firms, who can be threatened by coworkers safety comportments in the construction site), and a constant evolution of teams.

As a final consequence of the subcontracting system, far from the leading firms, the formal organisation is dissolved and people are employed without control of their ability to do the job before being onsite, or of their safety measures information. They are not only "undeclared" workers, which are a common reality in many sectors, such as demanding agricultural works or seasonal jobs, but also "un-controlled" workers, who may be friends, family, fellow-citizens, even young and inexperienced workers employed to help others. The cleaning sector is quite familiar with that functioning.

Those multiple layers of employment, status and subcontractors create confusion over regulatory responsibilities for the health and safety of workers. Thus, those in the industry are grappling with challenges of managing a culturally diverse workforce within a hazardous working environment, without having a precise estimation of the employment situation and without fully controlling the cultural diversity of the workers. The leading firms do not even try to integrate those layers of diversity, and their impact on safety management. During our explorative work, we had the opportunity to work on 
the "injury census program" of a master-builder. A striking observation was that the enterprise had two different census precisions, for its own employees, and for the subcontractors ones. The census system for its own employees was a much precise one, which showed a clear double standard mentality in the leading firms. Paraphrasing (Eakin, 1992), we could say there is deleterious "leaving it up to the subcontractors" attitude regarding safety of workers on working sites.

In a context of competition, $\mathrm{OH} \& \mathrm{~S}$ prevention is a difficult task to be dealt with. The difficulty is reinforced by the variable outcome of worker's interpretation of obligations due to their personal, collective or professional cultural background. The lack of knowledge actors possess regarding the OH\&S system prevent them from developing good practices which can emerge from diversity. The need of a comprehensive study has been expressed several times during our explorative interviews by both the large company's managers and the OHS advisors.

\section{As a conclusion: an on-going qualitative research on $O H \& S$ and cultural diversity in the French construction sector}

In line with the observations developed in this paper, the issue of cultural diversity and its impact on the $\mathrm{OH} \& \mathrm{~S}$ management in the French construction sector is subject to an on-going qualitative research conducted by the Ecole des Mines de Paris (Mines ParisTech) in relation to an international research cluster (Boocock et al., 2010).

Our research question could be formulated as follows: how the cultural diversity, as a narrative (attribution of origins, sense of belonging, identity creation) or a reality (language frontier, religious values, skills, professional experiences) may influence risk perception and behaviours in the French construction sector? Notwithstanding a marked mastering of the subcontracting system, most of the large firms are not able to take into account the cultural factors when designing prevention measures. Our research thereby aim at providing relevant first-hand data to help managers teams and $\mathrm{OH} \& \mathrm{~S}$ advisors in understanding the interactions at stake between cultural diversity and $\mathrm{OH} \& \mathrm{~S}$ risks.

One of the first observations regarding our field of research is the difficulty to collect precise data on migrant workers, their working conditions and OH\&S risk vulnerability (Lamm, Martin and Shulruf, 2009; Boocock et al. 2010). In many cases, migrants refuse to be part of a survey, since their often precarious employment prevents them from sharing a judgement on their living conditions and on their opinion on their working situation. Reaching both employers and employees in the same environment is a very challenging task due to their reluctance to talk to researchers outside their "confidence zone" (McKay et al., 2005; Banton 2008). The ethical issues of researching so-called "invisible workers", that is to say the fact that invisible workers are not invisible anymore from the moment they are surveyed, also have to be examined (Lamm, Martin and Shulruf, 2009; Boocock et al., 2010).

Our field research is to be composed of both observations (participant and non-participant observations) and interviews (directed and non-directed ones). The observations aim at collecting data from construction sites gathering characteristics in line with the research topic. The study will be conducted in the southern part of France, in a border region: Provence-Alpes-Cote-d'Azur. It is bounded by the Italian border to the East, the Mediterranean Sea to the South, and has a long history of African and European migration. The selected construction sites must gather several nationalities in the working environment, be they brought by foreign subcontractors or migrant workers. The small businesses must also be the majority on-site organisational level - the experienced management level of the workers - but in the mean time, the master-builder must be a larger firm. As SMEs are the relevant observation level, their interaction with leading enterprises regarding safety prevention and diversity management are part of our research. The explorative observations and interviews have been carried out. The interviews with the workers and the management chains of contractors have to be conducted by the following year: the interviewees will be workers, architects, control offices managers and $\mathrm{OH} \& \mathrm{~S}$ supervisors, from both SME and leading companies.

The theoretical background of the field study will be the grounded theory (Glaser and Strauss, 1967) and iterative research. From the hypotheses exposed in the introduction of this paper, we plan to apply the conceptualizing categories' method (Paillé and Mucchielli, 2008) to conduct our research on a constant back-and-forth movement between field data and analysis.

As (Mearns and Yule, 2009) clearly show, it does not seem possible to reduce such an analysis to pure organisational or pure cultural factors. OH\&S causalities are multifaced. The current subcontracting net in the construction sector worldwide, and specially in France, as well as its linked increase of cultural diversity in the working sites raise and modify the overall complexity of the system. A constant link to field realities is believed to prevent the risk of essentialism attached to any study taking cultures or perceptions as a research subject. The international research cluster, providing data from different national contexts also plays a role of control and of information crossing.

\section{Bibliography}

Banton, M. (2008). What the study of migration might contribute to the study of community. International Journal of Social Research Methodology. 11(2). 117-120.

Barmeyer, C., Mayrhofer U. (2002). Le management interculturel : facteur de réussite des fusions- 
acquisitions internationales ? Gérer et Comprendre. 70. 24-33.

Berretima, A-H. (2009). Du chantier à l'expertise médicale : la santé des travailleurs immigrés en question. Mouvement. http://www.mouvements.info/Du-chantier-a-1expertise-medicale.html (accessed November 2010).

Boocock, M., Hannif, Z., Jamieson, S., Kjær, T., Lamare, R., Lamm, F., Markey, R., Martin, C., Mcdonnell, N., Rasmussen, E., Robertson, C., Schweder, P., Shulruf, B. and Wagstagffe, M. (2010). OHS of Migrant Workers: an International Concern. Workshop on Health and Safety and Vulnerable Workers in a Changing World of Work, London, 8th June 2010.

Chevrier, S. (2003). Le management interculturel, Paris : PUF

Champoux, D. and Brun, J.P. (2000). Prise en charge de la sécurité dans les petits établissements des secteurs de l'habillement et de la fabrication des produits en métal. Montréal.

Commissariat Général au Développement Durable. (2009). L'activité et l'emploi de la construction : un début de repli en 2008 qui s'accentue en 2009. Le point sur. 23.

DARES. (2009). Les conditions de travail des salariés immigrés en 2005. Premières Synthèses. 09.2.

Daveziès, P. (1997). Processus de précarisation, organisation du travail, santé mentale. In Appay, B. and Thebaud-Mony, A. (eds). Précarisation sociale, travail et santé. Paris: Institut de recherche sur les sociétés contemporaines.

Eakin, J. (1992). Leaving it up to the Workers: Sociological Perspective on the Management of Health and Safety in Small Workplaces. International Journal of Health Services. 22. 689- 704

FFB. (Fédération Française du Bâtiment). (2010). Conférence de presse - intervention de Didier Ridoret, président de la FFB. Paris.

Glaser, B. G. and Strauss, A. L. (1967). The Discovery of Grounded Theory: Strategies for Qualitative Research, Chicago: Aldine Publishing Company.

Greene, B. (2000). Independent contractors: an attractive option? New Zealand Journal of Industrial Relations. 25/2. 183-205.

Hofstede, G. (1980). Culture's Consequences. International Differences in Work-Related Values. London: Sage Publications.
Hofstede, G. (2001). Culture's consequences: Comparing Values, Behaviours, Institutions and Organizations across Nations. London: Sage Publications.

INSEE. (1995). Enquête sur l'emploi. Paris.

INSEE. (2009). Emploi salarié et non salarié au 31 décembre 2008. http://www.insee.fr/fr/themes/tableau.asp?ref_id=na tnon03146 (accessed November 2010)

Irastorza, X. (2010). Migrant workers and OSH. Workshop on Health and Safety and Vulnerable Workers in a Changing World of Work. London. 8th June 2010.

D'Iribarne, P. (1989). La logique de l'honneur, gestion des entreprises et traditions nationales. Paris: Seuil.

Jounin, N. (2009). Chantier interdit au public, enquête parmi les travailleurs $d u$ bâtiment. Paris: La Découverte.

Kouabenan, D. R. (2009). Role of beliefs in accident and risk analysis and prevention. Safety Science. 47. 767-776.

Lamm, F. (2002). OSH in Small Businesses. In Lloyd, M. (ed.) Occupational Health and Safety in New Zealand: Contemporary Social Research. Wellington: Dunmore Press. 93-118.

Lamm, F., Medonnell, N., Martin, C. and Shulruf, B. (2009). Managing OHS in small Culturally Diverse workplaces: Developing a Research Agenda. Roundtable USE 2009: Understanding Small Enterprises. International Conference. Elsinore, Denmark 20-23 October 2009.

Martin, C. and Guarnieri, F. (2008). Pratiques de prévention des risques professionnels dans les $P M E-P M I$. Paris: Lavoisier.

McKay, S., Craw, M. and Chopra, D. (2006). Migrant workers in England and Wales: an assessment of migrant worker health and safety risks. Working Lives Research Institute. London Metropolitan University. London.

McKay, S. and Winkelmann-Gleed, A. (2005). Migrant workers in the East of England. London: London Metropolitan University.

Mearns, K. and Yule, S. (2009). The role of national culture in determining safety performance: Challenges for the global oil and gas industry. Safety Science. 47. 777-785.

Ministère de l'Economie, de l'Industrie et de l'Emploi. (2009). Importance des TPE/PME dans l'économie nationale en 2007. Chiffres-clés des TPE-PME. http://www.pme.gouv.fr/economie/chiffresclefstpe/i mportance.pdf (accessed November 2010) 
Organisation for Economic Co-operation and Development, (OECD). (2007). The Future of International Migration to OECD Countries.

OPPBTP. (2009). l'OPPBTP en action, rapport d'activité 2008. www.oppbtp.fr/content/download/9520/67228 (accessed November 2010).

Paillé, P. and Mucchielli, A. (2008). L'analyse qualitative en sciences sociales. Paris: Armand Colin.

Quinlan, M. and Mayhew, C. (2001). Evidence versus ideology: lifting the blindfold on OHS in precarious employment. Working Paper. UNSW. Sydney.

Quinlan, M. and Thébaud-Mony, A. (2010). La soustraitance et la SST dans les petites entreprises : une relation négligée. Risque, Sécurité, Environnement. 5, available at: http://www.rsemag.com/article.php?numero=12 7 (accessed November 2010).

Sargeant, M. and Tucker, E. (2009). Layers of vulnerability in OHS for migrant workers: case studies from Canada and the UK. Policy and Practice in Health and Safety. 7(2). 51-73.

Smith, P. M. and Mustard C. A. (2010). The unequal distribution of occupational health and safety risks among immigrants to Canada compared to Canadian-born labour market participants: 19932005. Safety Science. 48. 1296-1303.

Tavan, C. (2006). Migrations et trajectoires professionnelles, une approche longitudinale. Economie et statistique. 393-394. 81-99.

Walters, D. (2001). Health and Safety in Small Enterprises, European Strategies for Managing improvement. Brussels: P.I.E.-Peter Lang S.A. 